\title{
LEITURA E PRODUÇÃO TEXTUAL NO ENSINO MÉDIO: UMA PROPOSTA A PARTIR DA LINGUÍSTICA TEXTUAL
}

\author{
READING AND TEXTUAL PRODUCTION IN HIGH \\ SCHOOL: A PROPOSAL FROM THE TEXTUAL \\ LINGUISTICS
}

Patricia dos Santos"
Vaima Regina Alves Motta**

Resumo: Este artigo reporta-se a uma prática docente realizada com estudantes de Ensino Médio, de uma Escola da Rede Pública de Cruz Alta - RS, na disciplina de Língua Portuguesa, em 2009. As atividades desenvolvidas foram de leitura, interpretação e compreensão textual e de produção de textos. A Linguística Textual respalda o referido trabalho com base em Marcuschi (2008) e Koch (2003), além dos Parâmetros Curriculares Nacionais (2000) e das Orientações Curriculares para o ensino médio (2006). Foram trabalhados diversos gêneros textuais do campo argumentativo. A prática docente exercida obteve resultados bastante positivos, pois os estudantes foram bastante participativos e assíduos, além de ampliarem suas habilidades textuais e linguísticas.

Palavras-Chave: Leitura. Compreensão. Produção Textual.

ABSTRACT: This article refers to a teaching practice carried out with students from high school, a School of Public Network Cruz Alta - RS, in the discipline of Portuguese Language in 2009. The activities were reading, interpretation and textual understanding and production of texts. Linguistics Textual supports such work based on Marcuschi (2008) and Koch (2003), in addition to the National Curriculum Parameters (2000) and the Curriculum Guidelines for Secondary Education (2006). Various genres of the argumentative field were worked. The exerted teaching practice obtained very positive results because the students were very participatory and regulars, plus textual and expand their language skills.

KeYwords: Reading. Understanding. Text Production.

\footnotetext{
"Mestranda em Estudos Linguísticos, vinculada à linha de pesquisa Linguagem e Interação do Programa de Pós-Graduação em Letras (PPGL) da Universidade Federal de Santa Maria - UFSM. patriciasantosjj84@gmail.com

"* Professora adjunta na Universidade Federal de Santa Maria, vinculada à linha de pesquisa Linguagem e Interação do Programa de Pós-Graduação em Letras (PPGL) da Universidade Federal de Santa Maria - UFSM. vaimamotta@gmail. com
} 


\section{CONSIDERAÇÕES INICIAIS}

O trabalho, aqui exposto, trata-se de um artigo elaborado a partir de uma prática docente realizada durante o Estágio Curricular Supervisionado III, em Língua Portuguesa, do Curso de Letras - habilitação Português/ Inglês - e suas respectivas Literaturas, da Universidade de Cruz Alta - UNICRUZ.

A referida prática aconteceu durante o primeiro semestre do ano de 2009, numa Escola da Rede Pública Estadual da cidade de Cruz Alta - RS, com estudantes do $1^{\circ}$ ano do Ensino Médio, e teve por objetivo o trabalho com atividades de leitura e de produção textual, visando ao aprimoramento das competências e habilidades textuais dos sujeitos envolvidos.

Baseando-se em Vygotsky, Rojo (2000) acredita que a aprendizagem só é possível quando o que se pretende ensinar materializa-se na interação social entre os sujeitos, mediada pela linguagem. Quando pretende-se "formar" pessoas críticas e democráticas, é na própria sala de aula que se devem instaurar essas possibilidades de aprendizagem. É, pois, permitindo a emergência das situações controversas, das polêmicas, das divergências que se acerca das condições para a produção de enunciados que formarão a própria consciência crítica e ética dos sujeitos/estudantes.

Após constatar-se, nas aulas de Língua Portuguesa - durante as observações que antecederam ao período de regência - a necessidade de contribuir para uma prática de ensino que desse maior enfoque ao processo de leitura e de produção de textos, em sala de aula, proporcionando aos estudantes maior contextualização do ensino às suas próprias experiências, o objetivo era dinamizar o ensino e contextualizá-lo, haja vista a preocupação em se trabalhar a linguagem de maneira dinâmica, interativa e reflexiva.

Em virtude de tais aspectos, faz-se necessário esclarecer que o trabalho com ensino e aprendizagem de produção textual se deu a partir da perspectiva sociointerativa ${ }^{1}$. Tal perspectiva toma a língua como uma atividade cognitiva, sociohistórica e sociointerativa, pois observa seu funcionamento cognitivo, social e histórico.

Neste sentido, as Orientações Curriculares para o Ensino Médio (BRASIL, 2006) norteiam o ensino de Língua Portuguesa no Ensino Médio para que este propicie ao estudante/ educando um refinamento das habilidades de leitura/escrita e de fala/escuta - haja vista que a leitura e a escrita são ferramentas de empoderamento e inclusão social - e situações de interação, considerando-se as formas pelas quais se dão a produção, a recepção e a circulação de sentidos. Ressaltam, também, que a noção de práticas de linguagem compreende o processo de inserção dos sujeitos nas práticas sociais, que têm a linguagem como mediadora de ações.

Assim sendo, a proposta visava explorar os conteúdos programáticos aliando o trabalho com leitura, interpretação textual e produção de textos para que os estudantes envolvidos vivenciassem experiências textuais/ linguísticas que fortalecessem o ato de ler e de escrever não só na escola como em suas práticas diárias de linguagem.

${ }^{1}$ Para saber mais acerca de tal perspectiva, ver, por exemplo, Marcuschi (2008, p. 58 -68). 
Para Kato (1986), a função da escola na área de linguagem é introduzir a criança no mundo da escrita, tornando-a um cidadão funcionalmente letrado, isto é, um sujeito melhor capacitado para fazer uso da linguagem escrita para sua necessidade individual de crescer cognitivamente e para atender às várias demandas de uma sociedade que prestigia esse tipo de linguagem como um dos instrumentos de comunicação.

Dolz \& Schneuwly (2004) afirmam que na sua missão de ensinar os estudantes a escrever, ler e falar, a escola sempre realizou um trabalho com gêneros, haja vista que toda forma de comunicação cristaliza-se em formas específicas de linguagem. Os autores concebem que é por meio dos gêneros que as práticas de linguagem materializam-se nas atividades dos estudantes.

Um dos principais objetivos deste estudo, nesse sentido, foi o de conscientizar os estudantes para a importância da leitura de textos e, a partir daí, desenvolver a interpretação e a compreensão textual. Posterior a isso e, já mais conscientes da necessidade da leitura e da escrita, os estudantes envolvidos foram, então, convidados a escrever sua produção textual, tendo como base o texto que fora previamente apresentado e debatido em sala de aula.

Assim, apresentamos a seção abaixo, que tratará da teoria que sustenta e direciona o presente trabalho - a Linguística Textual bem como trará o breve histórico percorrido pela teoria e o seu objeto de investigação.

\section{Linguística TeXtual: A TEORIA DO TeXTO}

A Linguística Textual (LT) surgiu em meados dos anos 60, século XX, e atualmente trata da produção e da compreensão de textos orais e escritos. Anteriormente, como se sabe, a teoria apenas se ocupava de textos escritos e do seu processo de produção. Já nos anos $90^{2}$, seus interesses e objetivos se ampliaram de forma significativa.

De acordo com Marcuschi (2008), sob um ponto de vista mais técnico, por assim dizer, a Linguística Textual pode ser definida como o estudo das operações linguísticas, discursivas e cognitivas, reguladoras e controladoras da produção, bem como da construção e do processamento de textos orais ou escritos em contextos de uso.

Em sentido mais amplo, pode-se afirmar que a Linguística Textual é uma perspectiva de trabalho que observa, sobretudo, o funcionamento da língua em uso, pois se funda numa concepção em que a preocupação maior recai sobre os processos - sociocognitivos - e não no produto em si. A teoria dedica-se, ainda, à produção de sentidos, aos processos de compreensão, às operações cognitivas, à diferença entre os gêneros textuais, à inserção da linguagem em contextos e ao aspecto social da língua ${ }^{3}$ (MARCUSCHI, 2008).

Assim, Koch (2003) propõe que o texto seja entendido como objeto central do

\footnotetext{
${ }^{2}$ Para maiores esclarecimentos sobre o percurso e o desenvolvimento da Linguística Textual nos últimos anos, ver MARCUSCHI, L.A. Linguística de Texto: o que é e como se faz. Recife: UFPE, 1983; FÁVERO, L. L. \& KOCH, I. V. Linguística Textual: introdução. SP: Cortez, 1983 e MUSSALIM, F \& BENTES, A. C. (Orgs) Introdução à Linguística - domínios e fronteiras. V. 1. SP: Cortez, 2001.

${ }^{3}$ Sobre tais aspectos, ver Beaugrande (1997).
} 
ensino, isto é, que se priorizem, nas aulas de língua portuguesa, as atividades de leitura e produção de textos, levando o estudante a refletir sobre o funcionamento da língua nas diversas situações de interação verbal, sobre o uso dos recursos que a língua lhes oferece para a concretização de suas propostas de sentido, bem como sobre a adequação dos textos a cada situação.

Nesse viés, Marscuhi afirma:

Pelo fato de o texto ativar estratégias, expectativas, conhecimentos linguísticos e não linguísticos, a LT assume importância decisiva no ensino de língua e na montagem de manuais que buscam estudar textos. Ela deve prestar um serviço fundamental na elaboração de exercícios de produção e compreensão de textos (MARCUSCHI, 2008, p. 75).

A partir das concepções do autor, constata-se que a Linguística Textual toma por objeto não apenas o texto, mas também os sujeitos envolvidos e o(s) contexto(s) de produção e recepção de tais textos. A leitura e a escrita de textos são atividades permanentes da condição do ser humano, uma habilidade a ser compreendida e trabalhada.

De acordo com a Linguística Textual, um texto enquanto unidade comunicativa deve seguir um conjunto de critérios de textualização, haja vista que ele não é um aglomerado de frases, nem uma sequência aleatória de enunciados.

Os critérios de textualidade, definidos por Beaugrande \& Dressler ${ }^{4}$, vale ressaltar, não devem ser vistos de maneira isolada e/ou estanque, pois alguns critérios se complementam. Os critérios e/ou fatores de textualidade são sete, a saber: coesão, coerência, intertextualidade, intencionalidade, informatividade, aceitabilidade e situacionalidade.

A seguir, esquema dos critérios de textualidade para melhor visualização e entendimento:

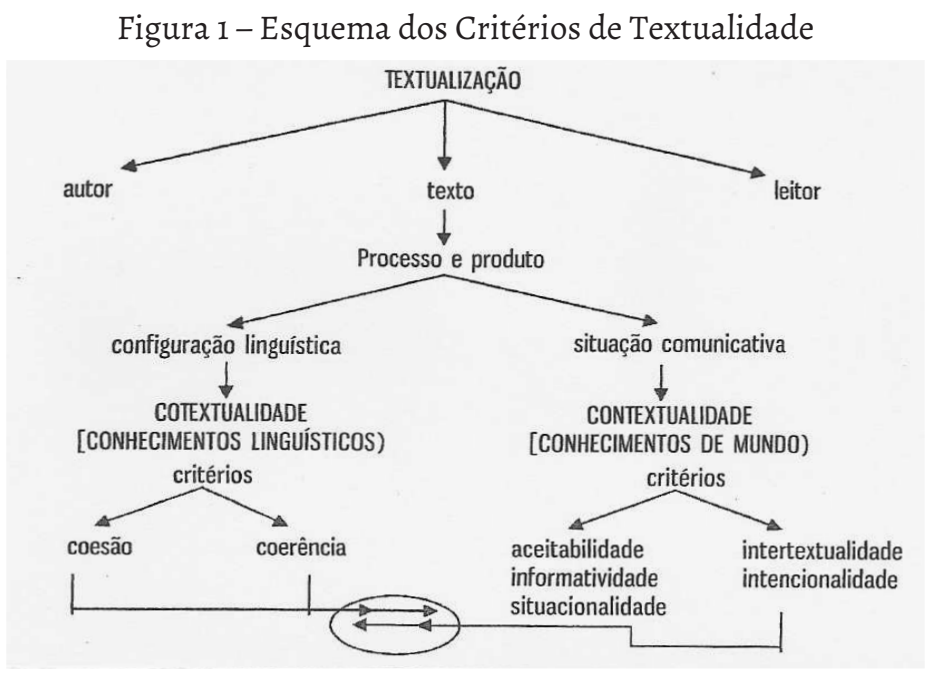

Fonte: Marcuschi (2008, p. 96)

${ }^{4}$ Acerca de uma melhor compreensão sobre tais critérios de textualidade, ver Beaugrande \& Dressler (1981). 
O processo de textualização envolve texto, autor e leitor. O texto, por sua vez, é tido como processo e produto. A partir do texto, podemos depreender aspectos cotextuais conhecimentos linguísticos - e aspectos contextuais - conhecimentos de mundo. Nesse sentido, têm-se os sete critérios de textualidade: coesão e coerência que convergem para os conhecimentos linguísticos, centrados no texto, enquanto aceitabilidade, informatividade, situacionalidade, intertextualidade e intencionalidade estão para os sujeitos que produzem e recebem o texto.

\section{Metodologia e Métodos}

No intuito de corroborar com o presente estudo, traz-se entendimento da Secretaria de Educação Básica, que ao encaminhar para os professores o documento Orientações Curriculares para o Ensino Médio (BRASIL, 2006) reforça a intenção de apresentar um conjunto de reflexões que alimente a prática docente, pois a qualidade da escola é condição essencial de inclusão e democratização de oportunidades e o desafio de oferecer uma educação básica de qualidade para a inserção do aluno e a consolidação da cidadania é tarefa de todos.

As Orientações Curriculares para o ensino médio - de Língua Portuguesa (BRASIL, 2006) alertam, ainda, que o professor deve ter em mente, ao ler tais orientações, que a proposição de tal texto é tarefa que se realiza por meio da discussão e da defesa de uma concepção de ensino orientadora tanto da emergência de objetos de ensino/estudo quanto das abordagens a serem adotadas nessa tarefa.
As orientações não devem ser tomadas como "receitas" ou "soluções" para os problemas e os dilemas do ensino de Língua Portuguesa, e sim como referenciais que, uma vez discutidas, compreendidas e (re)significadas no contexto da ação docente, possam efetivamente orientar as abordagens a serem utilizadas nas práticas de ensino e de aprendizagem. Assim, esclarece-se que a turma de Ensino Médio, na qual foram realizadas as observações e posteriormente ministradas trinta (30) horas/aula, aparentemente, demonstrava-se bastante dispersa e desmotivada. Constatou-se que seria oportuno proporcionar aos estudantes a uma prática pedagógica com enfoque em uma metodologia interativo-reflexiva.

Para embasar a ideia principal do referido projeto de ensino, isto é, a do trabalho com Língua Portuguesa, em sala de aula, enfocando leitura, interpretação e produção textual, cita-se Kato (1998):

A escola deveria desenvolver atividades de leitura-escrita e produção textual de forma sistemática e permanente, que propiciasse ao aluno a aquisição da linguagem, em suas modalidades. Para tanto, cabe incentivar o envolvimento do aluno com o texto de diálogo cultural, valorizando seu conhecimento, em especial, sua escrita e mostrando ao aluno a importância em posicionar-se frente a outras opiniões, sem, contudo, desrespeitar o seu autor. (...) Assim, poderá haver uma participação mais ampla na vida social de alunos e professores, a partir do momento em que juntos realizarem atividades comprometidas com a realidade, vivenciando 
direitos e deveres inerentes a cada cidadão. (KATO, 1998, p. 96)

Um dos muitos textos lidos e explorados, juntamente com os estudantes, em aula, foi a crônica "Dever de Cordialidade", de Paulo Santana, veiculada pelo Jornal Zero Hora, em 2005. O plano de aula previa realização de breve debate/discussão acerca da temática, no caso, as boas maneiras/a boa educação, e posteriormente os participantes realizaram produção de textos.

Para o trabalho com gêneros textuais/ discursivos em sala de aula, adotou-se a perspectiva de gênero de Dolz \& Schneuwly (2004), ou seja, que concebe os gêneros por agrupamentos (por exemplo: narrar, expor e argumentar).

Segundo tal perspectiva teórica “o gênero é um instrumento" (DOLZ \& SCHNEUWLY, 2004, p. 20). Para os autores, um instrumento media uma atividade, atribui-lhe certa forma; o instrumento, dessa feita, torna-se o lugar privilegiado da transformação dos comportamentos: explorar possibilidades, enriquecê-las, transformá-las são também maneiras de transformar a atividade que se vincula à utilização.

Conforme Dolz \& Schneuwly (2004), o instrumento, para se tornar mediador, transformador da atividade, necessita ser apropriado pelo sujeito; ele não é eficaz senão à medida que os sujeitos constroem os esquemas de sua utilização.

Ainda com base nos respectivos autores, os agrupamentos de gêneros se dividem em: narrar; relatar; argumentar; expor e descrever ações. Os autores defendem tal encaminhamento basicamente por três razões: oferece aos estudantes caminhos diferentes de acesso à escrita (princípio pedagógico da diferenciação); oferta a possibilidade de se definir especificidades de funcionamento dos diferentes gêneros e tipos para um trabalho de comparação de textos (ponto de vista didático) e por desenvolver as capacidades dos estudantes em domínios diversificados quanto a linguagem como instrumento de aprendizagem a serviço da reflexão sobre a relação do homem com o mundo e consigo mesmo (finalidades sociais do ensino) (DOLZ \& SCHNEUWLY, 2004).

Nesse sentido, Bazerman (2006) afirma que uma visão interacional de gênero pode auxiliar a expandir a pedagogia para fazer com que mais tipos de escrita se tornem mais significativos para os estudantes, proporcionando, assim, mais motivação na escolarização e abrindo as possibilidades para a escrita.

A partir de leitura e do debate sobre o texto/assunto mencionado, os estudantes tiveram momento para escrever seus próprios textos, agora no campo argumentativo, entregando as produções ainda em aula. Nesse viés, após entrega da avaliação da professora, houve novo momento de trabalho com os textos, no qual os participantes tiveram a oportunidade de realizar a reescrita dos textos.

De acordo com Kato (1986), o ato de escrever é um ato que envolve uma meta e um plano, além de ser uma resolução de problemas; pois há muito não se acredita mais que escrever seja uma simples questão de inspiração. Escrever envolve fase de pré-escritura e também de pós-escritura.

Reafirmando a importância de se trabalhar questões pertinentes ao texto, em sala de aula, cita-se Matêncio (1994) que diz que 
a atividade de escrita deveria estar sendo focalizada como processo, e não apenas como produto. Assim sendo, valorizar a escrita no que diz respeito ao seu processo de desenvolvimento implica também focalizar as diferentes etapas de produção: plano de organização, rascunho, reestruturação e revisão.

Vale ainda salientar que, juntamente com a produção textual, e valendo-se do interesse dos sujeitos envolvidos, foram trabalhadas questões de estrutura gramatical, aproveitando-se o enfoque nos temas abordados.

Conforme Suassuna (2009, p.4), "durante muito tempo, a prática da redação, limitou-se à elaboração de um texto escrito sobre um tema proposto (ou imposto), em que o aluno deveria por em prática as regras gramaticais aprendidas num momento anterior". Dentro dessa perspectiva, durante muito tempo, a prática da produção de texto (ou também técnicas de redação como era comumente conhecida) esteve balizada por paradigmas relativos às normas gramaticais (ortográficos, morfológicos, sintáticos etc), desconsiderando, assim, a dimensão textual-interativa, que envolve a produção de texto.

Entende-se, portanto, que a reiteração do ato de ler aperfeiçoa a escrita, amplia o vocabulário, desenvolve a capacidade interpretativa e mesmo a capacidade de expressão; portanto, é necessário comunicar-se de forma interativa e reflexiva.

\section{DisCUSSÕES IMPORTANTES}

O presente artigo teve o intuito de priorizar o trabalho, em âmbito escolar, com leitura, escrita e reescrita de textos, especialmente com uma turma de estudantes de Ensino Médio da Rede Pública Estadual de Cruz Alta-RS.

Procurou-se elaborar os conteúdos programáticos de maneira contextualizada, de forma a associar os assuntos aos fatos/temas da realidade e que fossem próximos do contexto de vida dos envolvidos, dinamizando, assim, a prática docente exercida.

A intenção maior foi a de fomentar a participação dos sujeitos envolvidos, haja vista que cabe ao professor o papel de educar, orientar e oportunizar o aperfeiçoamento textual e linguístico dos estudantes.

Segundo Marcuschi (2008), a Linguística Textual configura uma linha de investigação interdisciplinar dentro da Linguística e como tal exige métodos e categorias de diferentes procedências. A LT - na visão do autor - é, atualmente, a perspectiva que vem fornecendo a base teórica mais difundida no estudo da língua, no âmbito da sala de aula.

Sendo assim, além da escrita e da oralidade, aspectos relativos à argumentação e ao raciocínio lógico também estão imbricados no que tange ao trabalho com a língua materna. No que tange aos aspectos gramaticais, por exemplo, Marcuschi assevera que tal questão "trata-se de valorizar a reflexão sobre a língua, saindo do ensino normativo para um ensino mais reflexivo" (MARCUSCHI, 2008, p. 55).

O hábito de ler e escrever precisa ser incentivado e priorizado, em sala de aula, pois esta é, de fato, uma das funções atribuídas ao professor. Pensar a sala de aula e o texto 
como um lugar de interação e de reflexão de questões sociais, por exemplo, auxilia no processo de constituição das práticas orais e escritas às quais estamos submetidos na vida e na sociedade.

De acordo com Koch \& Elias (2006), a concepção de leitura é uma atividade de produção de sentido, que se baseia, por sua vez, na interação autor-texto-leitor. Logo, segundo as autoras, na atividade de leitura, ativamos lugar social, vivências, relações com o outro, conhecimentos textuais e outros elementos.

Assim, pode-se dizer que se lê para entender e conhecer, bem como para aprender e ficar informado. Lê-se, ainda, para questionar e solucionar problemas. Entende-se que a falta de domínio da leitura causa dificuldades na atividade de produção de textos. O professor poderá, em sala de aula, criar uma situação de estímulo e entusiasmo, sensibilizando o estudante à leitura. Embora nem todos os jovens venham a ser leitores habituais por toda a vida, deverão estar aptos a ingressar no mundo da leitura e da imaginação.

Para Marcuschi (2008), o trabalho com a língua portuguesa, na perspectiva de uma Linguística de Texto, tem de se ocupar com algo mais do que o ensino e a aprendizagem de regras ou normas em sequências linguísticas. Em sua visão, trata-se de um estudo em que se privilegia uma variada produção e suas respectivas contextualizações na vida cotidiana.

De acordo com Bazerman (2006), cabe aos professores ativar o dinamismo da sala de aula, de forma a manter os gêneros, solicitados aos estudantes, vivos em suas ações significativas de comunicação em âmbito escolar. Tal prática pode ser realizada, reitera o autor, ao se levar em conta a experiência prévia dos estudantes com tais gêneros.

A prática realizada com leitura e produção de textos propiciou, ainda, revisar aspectos gramaticais, ortográficos, de vocabulário, interpretação e compreensão textual, dentre outros.

\section{Considerações Finais}

Um trabalho com enfoque em leitura e produção textual faz-se de extrema importância, principalmente em se tratando de estudantes de Ensino Médio. O estudante percebe, desta forma, os objetivos do processo de ensino/aprendizagem em linguagem.

O estudante, por seu contexto diferenciado, necessita dos ingredientes acima referidos para ter acesso a uma educação linguístico-textual que venha a fortalecer e/ ou potencializar suas habilidades de leitura e escrita.

Conforme Marcuschi (2008), produtores e receptores de textos - escritor/leitor - devem colaborar para um mesmo fim. Os falantes/escritores da língua, quando produzem seus textos, enunciam conteúdos e sugerem sentidos, por sua vez, que devem ser construídos, inferidos e determinados mutuamente.

Nas palavras do autor:

A produção textual, assim como um jogo coletivo, não é uma atividade unilateral. Envolve decisões conjuntas. Isso caracteriza de maneira bastante essencial a produção textual 
como uma atividade sociointerativa (MARCUSCHI, 2008, p. 77).

A contextualização à realidade por meio da temática dos textos e dos próprios conteúdos trabalhados em sala de aula, também é fator importante para o sucesso de um trabalho de qualidade em educação. Quando o estudante percebe que o que se trata refere-se diretamente a ele e à sua vida, (como por exemplo, textos que venham ao encontro de sua realidade ou o trabalho com linguagem a partir de dificuldades/lacunas que este apresente) e, que o professor tem interesse real não só no seu crescimento como também no seu desenvolvimento nas habilidades textuais, cria-se um ambiente propício para a interação e a aprendizagem.

Tomando por base os Parâmetros Curriculares Nacionais para o Ensino Médio, de Língua Portuguesa, ressalta-se:

Quando deixamos o aluno falar a surpresa é grande, as respostas quase sempre surpreendentes. Assim, pode ser caracterizado, em geral, o ensino de Língua Portuguesa no Ensino Médio: aula de expressão em que os alunos não podem se expressar (BRASIL, 2000, p. 138).

A dinamização e a diversificação de atividades mostram-se recursos úteis e importantes neste processo. Ao referir-se a assuntos que de alguma maneira tocam a vida do sujeito, consegue-se prender sua atenção e pode-se levá-lo a trabalhar e produzir de forma mais consciente e ativa. Nesta atividade, o estudante estará aprendendo o conteúdo escolar, bem como aperfeiçoando sua capacidade de leitura e de produção textual.
Mais ainda, com o trabalho com gêneros do campo argumentativo, por exemplo, estará refletindo a respeito da importância de sua consciência de cidadão e leitor, de maneira construtiva, se o educador, que é um mediador, souber trazer questões e valores para serem debatidos e priorizados enquanto atividade de ensino e aprendizagem.

Ou seja, a proposta foi a de qualificar a prática docente das aulas de Língua Portuguesa, dinamizando tais momentos e proporcionando atividades de maior interação e, esta, por sua vez, mostrou-se totalmente válida, haja vista que os resultados foram condizentes com o esperado, os envolvidos participaram de forma ativa, consciente e motivada, considerando-se a realidade até então demonstrada nas observações realizadas.

Nesse interim, pode-se reforçar que, enquanto educador, o professor desde já está irremediavelmente comprometido com a educação como um todo e, nesse sentido, todo professor tem o dever de comprometer-se com o processo de aprendizagem do educando. Em se tratando de ser professor de Língua Portuguesa, há ainda uma preocupação maior: os ensinamentos gramaticais e linguísticos aliados a uma prática docente de interação-reflexão.

\section{REFERÊNCIAS}

BAZERMAN, C. Gênero, agência e escrita. Judith Hoffnagel e Angela Paiva Dionísio (organizadoras). São Paulo: Cortez, 2006.

BRASIL. SECRETARIA DA EDUCAÇÃO FUNDAMENTAL. Parâmetros Curriculares 
Nacionais (ENSINO MÉDIO). Parte I - Bases Legais. Brasília: Ministério da Educação, 2000. Disponível em: http://portal.mec.gov.br/seb/ arquivos/pdf/ blegais.pdf.

. SECRETARIA DE EDUCAÇÃO BÁSICA. Orientações curriculares para o ensino médio - Linguagens, códigos e suas tecnologias. Vol. 1. Brasília: Ministério da Educação, 2006. Disponível em http:// portal.mec.gov.br/seb/ arquivos/pdf/book_volume_or_internet.pdf. DOLZ, Joaquim \& SCHNEUWLY, Bernard. Gêneros orais e escritos na escola. Tradução e Organização Roxane Rojo e Glaís Cordeiro. Campinas, São Paulo: Mercado das Letras, 2004.

KATO, Mary A. No mundo da escrita - uma perspectiva psicolinguística. São Paulo: Editora Ática, 1986.

. O aprendizado da leitura. São Paulo: Martins Fontes, 1998.

$\mathrm{KOCH}$, Ingedore V. Linguística Textual: uma entrevista com Ingedore Villaça Koch. Revista Virtual de Estudos da Linguagem - ReVEL. Vol. 1, n. 1, agosto de 2003. [www.revel.inf.br].

\& ELIAS, Vanda Maria. Ler e Compreender: os sentidos do texto. São Paulo: Contexto, 2006.

MARCUSCHI, L. A. Produção textual, análise de gêneros e compreensão. São Paulo: Parábola Editorial, 2008.

MATENCIO, Maria de Lourdes Meirelles. Leitura, produção de textos e a escola: reflexões sobre o processo de letramento. Campinas, SP: Mercado das Letras, 1994.

ROJO, Roxane (ORG). A prática de linguagem em sala de aula. In: Praticando os PCNS. São Paulo: Mercado das Letras, 2000.
SUASSUNA, Lívia. Ensino de Língua Portuguesa: uma abordagem pragmática. Campinas, São Paulo: Papirus, 2009.

Recebido para publicação em 06 nov. 2015 Aceito para publicação em 05 set. 2016. 